\title{
Domissanitários ou domitóxicos? A maquiagem dos venenos
}

\author{
Household cleaning or household toxics? The camouflage \\ of poisons
}

\author{
Marcia Gomide da Silva Mello, Brani Rozemberg², Jane Silva Maia Castro³
}

\begin{abstract}
Resumo
O objetivo desta pesquisa foi avaliar o uso dos inseticidas usados no ambiente doméstico, relacionando-os com seus possíveis impactos na saúde e no ambiente. Utilizamos uma abordagem quantitativa-descritiva. Para coleta de dados, foram aplicados 125 questionários nas residências no município de Niterói, no Estado do Rio de Janeiro, entre 2009 e 2010, dos quais 50 foram realizados em um condomínio de classe média alta e 75 em uma comunidade de baixa renda. Nossos resultados demonstraram que $92 \%$ do grupo do condomínio e $77,3 \%$ do grupo da comunidade usam inseticidas. Os dois grupos pesquisados conheceram os inseticidas por meio das propagandas de televisão. Observamos nesta investigação que a vulnerabilidade do consumidor é independente da classe social, uma vez que todos se expõem aos inseticidas de alguma forma.
\end{abstract}

Palavras-chave: inseticidas domésticos; saúde pública; meio ambiente.

\section{Abstract}

The objective of this research was to evaluate the use of insecticides in households, relating them to their impact on health and the environment. We used a quantitative, descriptive approach. For data collection, 125 questionnaires were applied in homes in the municipality of Niterói, Rio de Janeiro state, in 2010. Of these, 50 were conducted in an upper middle class condominium and 75 were carried out in a low-income community. Our results showed that $92 \%$ of the upper middle class group and $77.3 \%$ of low-income group use insecticides. The two groups surveyed learned about insecticides through television advertisements. Consumers' vulnerability is high regardless of their social class, since both groups were exposed to risk in some way.

Keywords: household insecticides; public health; environment.

\footnotetext{
${ }^{1}$ Doutorado em Saúde Pública na Fundação Oswaldo Cruz (FIOCRUZ). Professora Associada no Instituto de Estudos em Saúde Coletiva, Universidade Federal do Rio de Janeiro (IESC/UFRJ) - Rio de Janeiro (RJ), Brasil.

${ }^{2}$ Doutorado em Saúde Pública na Fundação Oswaldo Cruz (FIOCRUZ). Pesquisadora no Centro de Pesquisas em Saúde do Trabalhador e Ecologia Humana da Escola Nacional de Saúde Pública da Fundação Oswaldo Cruz - Rio de Janeiro (RJ), Brasil.

${ }^{3}$ Doutorado em Saúde Pública e Meio Ambiente na Fundação Oswaldo Cruz (FIOCRUZ). Sanitarista no Setor de Vigilância em Saúde da Secretaria Estadual de Saúde do Rio de Janeiro - Rio de Janeiro (RJ), Brasil.

Trabalho realizado na Fundação Oswaldo Cruz, Escola Nacional de Saúde Pública - Rio de Janeiro (RJ), Brasil

Endereço para correspondência: Márcia Gomides - Praça da Prefeitura Universitária Rio de Janeiro - CEP: 21941-598 - Rio de Janeiro (RJ), Brasil - Email: gomide@iesc.ufrj.br

Fonte de financiamento: nenhuma.

Conflito de interesses: nada a declarar.
} 


\section{INTRODUÇÃO}

A legislação brasileira diferencia os produtos empregados na agricultura dos utilizados em ambientes confinados. O primeiro, segundo a Lei $\mathrm{n}^{\circ} 7.802$, de 11 de julho de $1989^{1}$, é classificado como agrotóxico, e os produtos químicos usados em ambientes confinados são classificados, de acordo com a Lei ${ }^{\circ} 6.360$, de 23 de setembro de $1976^{2}$, como saneantes domissanitários. A definição de domissanitários, conforme essa lei é dada como: "Substância ou preparação destinada à higienização, desinfecção ou desinfestação domiciliar, em ambientes coletivos ou públicos". Sua aprovação e seu registro dependem apenas da Agência Nacional de Vigilância Sanitária (ANVISA), vinculada ao Ministério da Saúde. Por esse motivo, eles escapam de ser classificados e fiscalizados como agrotóxicos ${ }^{3,4}$.

Esses produtos, usados para o controle de vetores no ambiente domiciliar, são inseticidas principalmente do grupo químico dos piretróides e piretrinas e estão entre as principais causas de intoxicação no ambiente doméstico, causando manifestações alérgicas especialmente em crianças ${ }^{4}$. Os consumidores, na maioria das vezes, desconhecem as propriedades tóxicas dos componentes das formulações. A banalização do consumo dessas substâncias químicas no ambiente doméstico, bem como o uso contínuo e simultâneo de várias delas, evidencia um risco elevado para a saúde pública e para o meio ambiente ${ }^{5}$.

O uso persistente de pesticidas é determinante no desenvolvimento de cepas resistentes que podem surgir como resultado do uso contínuo de inseticidas, os quais matam as espécies de mosquitos com alelos suscetíveis, mas que aqueles que possuem alelos resistentes. Assim, geram uma cepa de mosquitos que possuem características favoráveis à sobrevivência, mesmo sob efeito de inseticidas. O desenvolvimento dessa resistência é resultado de uma pressão sucessiva da seleção, ou seja, do uso frequente do mesmo inseticida ${ }^{6,7}$. Esse processo tem sido verificado para todas as classes de inseticidas, afetando, direta e profundamente, a reemergência das doenças transmitidas por vetores ${ }^{8}$, pois, apesar dos destacados avanços alcançados no desenvolvimento de métodos alternativos, os inseticidas químicos continuam sendo a principal ferramenta dos programas integrados de controle ${ }^{7}$.

Entretanto, as políticas de controle das doenças transmitidas por vetores continuam elegendo o controle químico ao vetor como estratégia principal de combate a essas doenças. A substituição de um veneno por outro mais potente não é o melhor caminho, principalmente pelas incertezas de seus impactos na saúde humana e no meio ambiente9.

Esse modelo de controle químico ao vetor utilizado no ambiente doméstico, associado a um consumidor motivado pela necessidade de proteção veiculada por propagandas indutoras, configura um cenário importante nesse processo de resistência do mosquito ao inseticida, sendo o consumidor a vítima de sua própria aquisição. É preciso que sejam mais sensibilizados e instruídos quanto aos produtos que compram. A legislação sobre a rotulagem dos inseticidas domésticos, por meio da resolução RDC no 326 , de 9 de novembro de $2005^{10}$, modificou a frase de advertência e permitiu a adição de odorizantes que mascaram o odor dos inseticidas, propiciando ao consumidor um maior risco de exposição ao produto.

Nesse cenário, o objetivo deste artigo é descrever as práticas de uso dos inseticidas no ambiente doméstico, relacionando-os com seus impactos na saúde e com as estratégias de divulgação adotadas pelos fabricantes desses produtos.

\section{PROCEDIMENTOS METODOLÓGICOS}

Esta pesquisa utilizou uma abordagem quantitativa-descritiva. Para a coleta de dados, foram elaborados e aplicados questionários com perguntas fechadas e abertas, bem como realizada a análise documental. O estudo foi desenvolvido no município de Niterói, localizado na região metropolitana do Estado do Rio de Janeiro. A região oceânica de Niterói foi escolhida devido ao seu crescimento desordenado e à sua degradação ambiental envolvendo populações de diferentes estratos sociais ${ }^{11}$. Entre os bairros que compõem a região oceânica, escolhemos o bairro de Itaipu pela sua alta concentração de mosquitos ${ }^{11}$. A coleta de dados, ocorrida entre maio de 2009 e julho de 2010, foi realizada por meio de visitas domiciliares realizadas pelos próprios pesquisadores, durante as quais foram aplicados os questionários. A população de estudo se constitui por dois grupos distintos, aqui designados como "Grupo Condomínio", conjunto de casas de classe média alta, e o "Grupo Colônia", composto por moradores cadastrados pelo Programa Médico de Família da Colônia de Pescadores de Itaipu. Utilizou-se o procedimento de amostragem sistemática. De cada quatro casas, uma entrevista era realizada. No Grupo Condomínio, foram visitadas 50 residências das 232 existentes no local. Das 371 residências cadastradas no Grupo Colônia, aplicou-se o questionário em 75 delas. Esses totais alcançados resultaram do aceite em participar da pesquisa. Definiu-se adulto(a) dono(a) de casa como critério de inclusão e ser menor de 18 anos como critério de exclusão. Quando permitido pelo informante, eram verificados os tipos de inseticidas presentes no domićlio e o seu acondicionamento, corroborando informações obtidas pelo questionário. Para tabulação dos dados e para o cálculo da frequência relativa e absoluta, utilizou-se o programa Microsoft ${ }^{\circledR}$ Office Excel 2003. A pesquisa foi submetida ao Comitê de Ética da Escola Nacional de Saúde Pública (ENSP) com o número do CAA 00210031000-09, atendendo às normas da Comissão Nacional de Ética e Pesquisa.

\section{RESULTADOS}

Nos 50 entrevistados do Grupo Condomínio, 72\% dos informantes eram do sexo feminino, e $28 \%$, do sexo masculino. Nos 75 entrevistados do grupo Colônia de Pescadores, 77,3\% eram do sexo feminino, e 22,7\%, do sexo masculino. O número 
de moradores por residência não diferiu entre os dois grupos, sendo em média encontrados 4 moradores por casa. Em relação ao número de crianças, na faixa etária menor que 10 anos, observou-se a sua presença em 36\% das casas do Grupo Colônia, enquanto que, no Grupo Condomínio, elas foram encontradas em $24 \%$ das residências. No tocante a animais de estimação, só $8 \%$ das casas do Grupo Condomínio não os possuíam, ao passo que, no Grupo Colônia, 36\% não residiam com nenhum animal de estimação. O cão é a espécie mais presente nos dois grupos: 80\% no Grupo Condomínio e 60\% no Grupo Colônia, no quais, em muitos casos, são criados soltos. Em relação às condições de saneamento, os dois grupos possuíam sistema de abastecimento de água, esgotamento sanitário e coleta de lixo, sendo que o Grupo Condomínio tinha um programa de coleta seletiva de lixo.

Devido às características ambientais da região, os mosquitos são o principal incômodo relatado nos dois grupos e associados ao uso dos agentes químicos. No Grupo Condomínio, 92\% participantes informaram usar inseticidas e apenas $8 \%$ dos entrevistados disseram que não usavam nenhum tipo de inseticida para o controle de mosquitos e de pernilongos, enquanto que, no Grupo Colônia, 77,3\% usavam inseticidas e $22,7 \%$ admitiram não fazer uso de inseticidas.

Quanto à forma de apresentação do inseticida, a mais utilizada nos dois grupos é o aerossol (64\% no Grupo Condomínio e 61,3\% no Grupo Colônia). O uso de repelentes é a segunda estratégia mais frequente no Grupo Condomínio (64\%), enquanto que, no Grupo Colônia, aparece como terceira opção (apenas 14,7\%). A segunda estratégia mais frequente para o Grupo Colônia é o uso do ventilador (26\%), mas que, no Grupo Condomínio, é substituída pelo o uso de pastilha para aparelho elétrico $(10,7 \%)$.

A legislação exige que a rotulagem do inseticida doméstico contenha o seu principal grupo químico e a sua composição química, mas a sua classe toxicológica não é informada no rótulo. Segundo a legislação, os inseticidas são classificados em três classes toxicológicas. A classe I (extremamente tóxica) não pode ser vendida para uso doméstico. As classes II (altamente tóxico) e III (moderadamente tóxica) são de venda livre ao consumidor ${ }^{12}$. Em relação aos repelentes, os chamados inseticidas cosméticos à base de dietiltoluamida (DEET), são vendidos sob as marcas comerciais de Autan $^{\circledR}$, Off $^{\circledR}$, Repelex $^{\circledR}$, em diferentes concentrações (5-30\%). As Tabelas 1 e 2 apresentam um resumo

Tabela 1. Inseticidas utilizados no controle de vetores no Grupo Condomínio na área de estudo, Niterói-RJ, 2010

\begin{tabular}{lccccc}
\multicolumn{1}{c}{ Nome comercial } & $\mathbf{N}^{\circ}$ de ocorrência & Percentual (\%) & Tipo classe produto & $\begin{array}{c}\text { Principal grupo } \\
\text { químico }\end{array}$ & Classe toxicológica \\
SBP & 31 & 62,0 & Inseticida & Piretroide & III \\
Off & 16 & 32,0 & Repelente & Amida & Amida \\
Off Kids & 10 & 20,0 & Repelente & Amida & $*$ \\
Autan & 6 & 12,0 & Repelente & Piretroide & III \\
Raid & 5 & 10,0 & Inseticida & Piretroide & III \\
Baygon & 3 & 6,0 & Inseticida & Piretroide & III \\
Creolina (UFFA) & 1 & 2,0 & Inseticida & Piretroide & III \\
Fort & 1 & 2,0 & Inseticida & III \\
K-othrine & 1 & 2,0 & Inseticidida & Organofosforado \\
Mafu & 1 & 2,0 & & II \\
\hline
\end{tabular}

*Não encontrado Fonte: Elaborada pelos autores. Os dados dos produtos foram obtidos dos rótulos dos inseticidas citados pelos informantes

Tabela 2. Inseticidas utilizados no controle de vetores do grupo Colônia de Pescador na área de estudo, Niterói-RJ, 2010

\begin{tabular}{|c|c|c|c|c|c|}
\hline Nome comercial & $\mathrm{N}^{\circ}$ de ocorrência & Percentual (\%) & Tipo classe produto & $\begin{array}{c}\text { Principal grupo } \\
\text { químico }\end{array}$ & Classe toxicológica \\
\hline SBP & 43 & 57,3 & Inseticida & Piretroide & III \\
\hline Baygon & 5 & 6,7 & Inseticida & Piretroide & III \\
\hline Off & 4 & 5,3 & Repelente & Amida & * \\
\hline Durma Bem & 3 & 4,0 & Inseticida & Piretroide & III \\
\hline Raid & 2 & 2,7 & Inseticida & Piretroide & III \\
\hline Off Kids & 1 & 1,3 & Repelente & Amida & * \\
\hline Repelente Johnson & 1 & 1,3 & Repelente & Amida & * \\
\hline Repelex & 1 & 1,3 & Repelente & Amida & * \\
\hline Creolina (UFFA) & 1 & 1,3 & Inseticida & Piretroide & III \\
\hline Triatox & 1 & 1,3 & Inseticida & Amitraz & III \\
\hline Querosene & 1 & 1,3 & Solvente & Hidrocarboneto & * \\
\hline Mortein & 1 & 1,3 & Inseticida & Piretroide & III \\
\hline
\end{tabular}

${ }^{*}$ Não encontrado 
da distribuição de consumo dos diferentes produtos nos dois grupos da pesquisa com as respectivas classificações toxicológicas.

Em relação aos cuidados com manuseio de inseticidas, 54\% dos informantes do Grupo Condomínio e 25,3\% dos informantes do Grupo Colônia disseram que não tomavam nenhum cuidado ao usar esses produtos. Entre os que tomavam cuidados no uso e no manuseio dos inseticidas, no Grupo Condomínio, $20 \%$ disseram que se preocupavam em não ficar no ambiente depois da aplicação. Já no Grupo Colônia, 50,7\% afirmaram que tomavam cuidado ao usar os inseticidas, principalmente em não ficar expostos ao produto (18,7\%) e ao seu cheiro (10,7\%).

Em relação ao local de armazenamento dos inseticidas domésticos, no Grupo Condomínio, 38\% guardavam esses produtos na cozinha/despensa, e 32\%, na área de serviço/lavanderia. Quanto ao Grupo Colônia, 21,3\% guardavam-nos no quarto, e $17,3 \%$, no banheiro.

Quanto à utilização de proteção mecânica, como telas nas janelas, nota-se que é uma prática pouco usada nos dois grupos. No Grupo Colônia e no Grupo Condomínio, 81,3 e 60\%, respectivamente, dos domicílios visitados não tinham telas nas janelas. O uso de mosquiteiros sobre as camas só foi encontrado em uma casa, nos dois grupos, uma prática simples de proteção não mais adotada pelas pessoas entrevistadas, sendo considerada ultrapassada pela maioria delas.

Na Tabela 3, observamos a frequência de utilização dos inseticidas nos domicílios, evidenciando uma diferença entre ambos. No Grupo Condomínio, 22\% dos entrevistados faziam uso dos inseticidas diariamente, $42 \%$ só aplicavam o inseticida quando havia inseto e $4 \%$ o utilizavam semanalmente. Já no Grupo Colônia, 16\% aplicavam inseticidas diariamente, 26\%, quando apareciam insetos, e 9,3\%, semanalmente.

Quanto à leitura dos rótulos das embalagens dos inseticidas, 60 e 29,3\% dos entrevistados, respectivamente, do Grupo Condomínio e do Grupo Colônia disseram que liam esses rótulos para conhecer os componentes e os cuidados no uso do produto.

Na Tabela 4, descrevemos os motivos pelos quais os entrevistados informaram não ler os rótulos dos inseticidas, e as principais justificativas, nos dois grupos, foram a falta de interesse e a preguiça. Verificou-se inclusive uma percentagem muito alta de recusa em responder à essa questão no Grupo Condomínio.

Em relação à forma de conhecimento dos inseticidas, no Grupo Condomínio, $54 \%$ disseram que foi por meio de propaganda na televisão, o mesmo ocorrendo com 40\% do Grupo Colônia. Quanto ao local de compra desses produtos, o supermercado foi indicado como o mais utilizado pelos dois grupos.

\section{DISCUSSÃO}

Os dados encontrados nesta pesquisa são concordantes com achados de pesquisas no Brasil sobre o tema ${ }^{13-15}$, indicando que o comportamento do brasileiro em relação à utilização de inseticidas é semelhante. Por exemplo, o uso de substâncias químicas para o controle de pernilongos e de mosquitos tem sido a estratégia domiciliar mais usada atualmente em contraposição

Tabela 3. Frequência de uso de inseticida na área de estudo, Niterói-RJ, 2010

\begin{tabular}{|c|c|c|c|c|c|}
\hline Grupo Condomínio & $\%$ & $\mathbf{N}$ & Grupo Colônia de Pescador & $\%$ & $\mathbf{N}$ \\
\hline $\begin{array}{l}\text { Aplica inseticida quando tem inseto } \\
\text { (barata, mosquito) }\end{array}$ & 42,0 & 21 & $\begin{array}{l}\text { Aplica inseticida quando tem inseto } \\
\text { (barata, mosquito) }\end{array}$ & 26,7 & 20 \\
\hline Aplica inseticida de vez em quando ou raramente & 28,0 & 14 & Não usa produto & 20,0 & 15 \\
\hline Aplica inseticida diariamente & 22,0 & 11 & Aplica inseticida diariamente & 16,0 & 12 \\
\hline Não informou & 12,0 & 6 & Aplica inseticida de vez em quando ou raramente & 14,7 & 11 \\
\hline Aplica inseticida $1 \mathrm{vez}$ na semana ou de $15 / 15$ dias & 10,0 & 5 & Prefere usar ventilador & 12,0 & 9 \\
\hline Não usa produto & 6,0 & 3 & Aplica inseticida 1 vez na semana ou de $15 / 15$ dias & 9,3 & 7 \\
\hline Dedetização $(1,2,3$ vezes ao ano $)$ & 6,0 & 3 & Aplica inseticida 2 vezes na semana & 5,3 & 4 \\
\hline Aplica inseticida 3 vezes na semana & 2,0 & 1 & Aplica inseticida 3 vezes na semana & 4,0 & 3 \\
\hline \multirow[t]{2}{*}{ Aplica inseticida 2 vezes na semana } & 2,0 & 1 & Aplica inseticida mais no verão & 2,7 & 2 \\
\hline & & & Não informou & 1,3 & 1 \\
\hline
\end{tabular}

Tabela 4. Motivo informado para a não leitura do rótulo do inseticida na área de estudo, Niterói-RJ, 2010

\begin{tabular}{|c|c|c|c|c|c|}
\hline Grupo Condomínio & $\%$ & $\mathbf{N}$ & Grupo Colônia de Pescador & $\%$ & $\mathbf{N}$ \\
\hline Não informou & 62,0 & 31 & Não lê porque não se interessa ou tem preguiça & 32,0 & 24 \\
\hline Não lê porque não se interessa ou tem preguiça & 12,0 & 6 & Não informou & 10,7 & 8 \\
\hline $\begin{array}{l}\text { Não lê porque acha as letras pequenas e não } \\
\text { enxerga }\end{array}$ & 8,0 & 4 & $\begin{array}{l}\text { Não lê porque acha as letras pequenas e não } \\
\text { enxerga }\end{array}$ & 9,3 & 7 \\
\hline Não lê por falta de hábito ou de tempo & 6,0 & 3 & Não lê porque conhece o produto & 9,3 & 7 \\
\hline \multirow[t]{2}{*}{ Não lê porque conhece o produto } & 2,0 & 1 & Não lê por falta de hábito ou de tempo & 6,7 & 5 \\
\hline & & & $\begin{array}{l}\text { Não lê porque acha que não faz mal, "ninguém } \\
\text { nunca lê" ou usa produto caseiro }\end{array}$ & 5,3 & 4 \\
\hline
\end{tabular}


ao uso de tela mecânica, cuja prática tem sido negligenciada. Nos dois grupos aqui investigados, ambas as situações foram observadas, com metade dos domicílios sem qualquer tipo de proteção mecânica. Deve-se considerar que a instalação de telas mosquiteiras, apesar de simples, demanda planejamento e tem custo elevado. Os motivos para a não adesão a esse tipo de proteção valeriam estudos mais aprofundados ${ }^{13,14}$.

Da mesma forma, a frequência da aplicação de inseticidas pelos dois grupos diariamente (22\% do Grupo Condomínio e 16\% no Grupo Colônia) é semelhante à encontrada em domicílios de Recife-PE, nos quais o uso de biocidas foi o método mais citado (67\%), sendo que $43 \%$ periodicamente, variando de uso diário (14,4\%), ao uso mensal (10\%) e semestral $(11,5 \% \text {. })^{15}$.

Esse é um dado importante que mostra a banalização do uso dos inseticidas como produtos inócuos e práticos, não sendo considerados seus malefícios na hora da compra, nem quanto ao custo monetário anual, nem quanto ao custo da saúde a médio e longo prazos. Os inseticidas com apresentação em forma de aerossol de uso contínuo com dispositivo automático e de pastilhas para aparelho elétrico foram as formas de apresentação que mais ocorreram no Grupo Condomínio. No Grupo Colônia, a forma de apresentação em aerossol também foi a que mais ocorreu, entretanto eram inseticidas em aerossol sem o dispositivo automático, de custo menos oneroso. Essas escolhas, decorrentes de distintas condições econômicas, apesar das inexpressivas diferenças, indicam o desejo de ambos em buscar a ilusória melhor proteção, seja do ponto de vista da eficiência, seja pela praticidade, em comparação ao uso de telas mosquiteiras.

Interessante ressaltar que o cheiro do produto no Grupo Colônia era entendido como sinal de risco, o que não ocorreu no Grupo Condomínio. Tal diferença, entretanto, pode estar associada à marca, ou ao "modelo" consumido, visto que alguns produtos utilizam mais o engodo de disfarce odorífico do que outros, sendo os mais baratos, como os do tipo espiral, por exemplo, mais malcheirosos. Quando o produto não tem cheiro ou tem odor agradável, as pessoas tendem a permanecer no local.

As diferenças entre os dois grupos pesquisados em relação ao local de armazenamento corroboram as pesquisas de Diel et al..$^{13}$, Malacco ${ }^{14}$ e Câmara et al. ${ }^{16}$, que apontam o local de armazenagem do grupo de menor renda, aqui identificados como quarto e banheiro, como promissor de maior risco às crianças devido ao seu fácil acesso aos inseticidas.

Mesmo que 60\% dos entrevistados do Grupo Condomínio e 29,3\% do Grupo Colônia tenham informado que liam os rótulos, não significa conhecimento das substâncias químicas, pois uma linguagem muito técnica acaba não informando ao consumidor o que ele precisa saber. Nesta investigação, nenhum dos informantes tinha conhecimento sobre a toxidade dos inseticidas, concordando com Câmara ${ }^{15}$ que a falta de preocupação e o desconhecimento da toxidade dos produtos utilizados são gerais.

Da mesma forma, pesquisas sobre rótulos de agrotóxicos apontam várias dificuldades de compreensão, tais como a utilização de linguagem técnica e de elaboração rebuscada, comprometendo o entendimento correto das mensagens pelos consumidores. Seria, portanto, fundamental que as normas reguladoras condicionassem a apresentação das informações técnicas ao usuário a uma sinonímia acessível ao cidadão comum, o qual não é obrigado a conhecer tal vocabulário e, portanto, não deve sofrer as consequências por ignorar a classificação de toxicidade ${ }^{13-15,17,18}$.

A atual legislação sobre rotulagem de inseticidas domésticos ameniza a advertência sobre o produto ao modificar a frase de advertência, “CUIDADO! PERIGOSO!", colocada na frente das embalagens, exigida pela RDC no 174 , de 8 de julho de $2003^{19}$, que altera o item L da Portaria n ${ }^{\circ} 321 / \mathrm{MS} / \mathrm{SNVS}$, de 28 de julho de $1997^{20}$, o qual regulamenta os Produtos Desinfetantes Domissanitários. Tal aviso foi revogado pela resolução RDC $\mathrm{n}^{\circ} 326$, de 9 de novembro de $2005^{10}$, que preconiza como advertência básica, inscrita na face do rótulo voltada para o consumidor, a frase "ATENÇÃO-CUIDADO", que vigora até os dias de hoje.

O rótulo impresso na embalagem tem como objetivo informar o consumidor sobre produto ali colocado. Porém, na maioria dos casos, existe uma dificuldade, por parte da população, de adquirir o hábito de lê-lo. O problema pode estar relacionado à compreensão das informações inseridas nos rótulos, cuja linguagem técnica só pode ser alcançada por um público mais específico. Pode, inclusive, estar relacionado ao perfil dos grupos, já que, no Grupo Condomínio, $60 \%$ dos entrevistados afirmam que têm o hábito de ler os rótulos, em contraposição ao grupo Colônia, no qual a porcentagem cai para $29 \%$. Em outras palavras, no grupo de menor poder aquisitivo, reduz-se pela metade a prática da leitura. Se considerarmos que a leitura por si só poderia proteger os cidadãos, estes estariam mais vulneráveis, apesar de ser notória a pouca eficiência dessa informação nos grupos pesquisados, já que não deixam de usar o inseticida, apesar da consulta ao rótulo. Percebe-se que há uma contradição quanto à finalidade da rotulagem de inseticidas. Ao mesmo em que representa o elo entre o consumidor e o produto, só é decifrada por aqueles que estão mais capacitados.

Esse cenário assemelha-se ao de compreensão de rotulagens de alimentos elaboradas com letras pequenas e com excesso de informação, cuja estratégia baseia-se em potencializar o descaso do consumidor a esse tipo de informação na hora da compra, chamando a sua atenção a outros quesitos ${ }^{21-23}$. A estratégia adotada nas embalagens dos inseticidas domésticos é também de chamar a atenção do consumidor para a compra do produto, dissuadindo-o a desconsiderar informações técnicas. À frente 
do rótulo, a maioria dos inseticidas usa imagens de flores de crisântemo e apresenta a água como solvente. Atrás estão as informações sobre o modo de usar, sobre a composição química, seus cuidados, advertências, em letras diminutas. As cores das embalagens também são estrategicamente escolhidas para atrair a atenção do consumidor sobre o produto. Segundo Farina ${ }^{24}$, o amarelo, o laranja, o preto ou o verde-escuro são as cores mais utilizadas para tal.

A cor, a forma e o texto das embalagens têm funções bem definidas na mensagem a ser transmitida e podem sugerir a qualidade de seu conteúdo aos olhos do consumidor. A cor da embalagem atua diretamente nas funções ópticas, fisiológicas e neurológicas. Na publicidade de promoção de vendas, vários fatores se conjugam para que a cor exata seja a portadora da expressividade mais convincente para cada tipo de mensagem a ser veiculada em um produto, influenciando na decisão de compra $^{25}$.

Contudo, além de ser influenciado pela embalagem em si, o conhecimento prévio sobre a existência do produto de modo indutor-confiável é necessário. Os dois grupos pesquisados apontaram a propaganda na televisão como veículo do conhecimento acerca do produto. Mas esse padrão de comportamento verificado nesta pesquisa difere do estudo de Malacco ${ }^{14}$, no qual o motivo para escolha do produto era ser "o de uso tradicional". É importante que ressaltar que 100\% dos informantes do Grupo Condomínio e 75\% no Grupo Colônia disseram que a propaganda influenciava no consumo, enquanto os $25 \%$ restantes informaram não ser influenciados.

Esse resultado apresenta uma diferença no alcance da propaganda entre os grupos pesquisados, sendo que a situação do Grupo Condomínio é preocupante, já que se mostra completamente confiante ao que vê nas propagandas televisivas. Isso deveria servir de alerta as "autoridades" de regulamentação publicitária, pois vender veneno maquiado como inofensivas fragrâncias ao ser humano deveria ser proibido.

A maioria das propagandas de alimentos, de produtos de limpeza e de inseticidas utiliza imagens de crianças. Essa questão envolve o embate ético e mercadológico que a propaganda enfrenta no uso de crianças como apelo persuasivo. Ao associar produtos que devem estar fora do alcance da criança, como os inseticidas, às imagens infantis, entendemos que a propaganda está ultrapassando os limites e contrariando a legislação em vigor $^{26}$.

A publicidade é uma modalidade de comunicação persuasiva. Serve aos interesses do anunciante e do fabricante do produto, o que costuma ser positiva e, por razões óbvias, tende a apresentar o lado atrativo e o maior benefício que o consumidor poderá obter. Qualquer aspecto negativo pode associar-se à marca e gerar uma atitude desfavorável a ela ${ }^{26}$.
O mercado competitivo atual, auxiliado pela mídia, com suas propagandas cada vez mais atrativas, ajudou na proliferação de produtos químicos com formulações diferentes e embalagens mais estimulantes ao consumidor. Eleva-se, assim, o número de produtos químicos domiciliares consumidos, contribuindo consideravelmente para a degradação do meio ambiente ${ }^{27}$.

No entanto, é do conhecimento de toda população o grande domínio que os meios de comunicação de massa possuem. Aquilo que é veiculado na televisão, rádio, revistas e jornais, seja uma notícia, seja uma campanha publicitária, acaba por introduzir-se no campo das convicções do indivíduo sem que haja uma análise prévia e minuciosa dos fatos. Tal é a razão pela qual o Estado interveio por meio do código de defesa do consumidor (CDC), determinando normas que possuem por finalidade regular a publicidade e, com isso, proteger o consumidor, minimizando sua vulnerabilidade.

No Direito, a vulnerabilidade é o princípio segundo o qual o sistema jurídico brasileiro reconhece a qualidade do(s) agente(s) mais fraco(s) na(s) relação(ões) de consumo ${ }^{28}$. Logo, podemos afirmar que a vulnerabilidade do consumidor é absoluta, independente da classe social a que pertence. A atitude das indústrias em adicionar substâncias odoríferas aos inseticidas é uma das estratégias de ocultação do risco. A exposição aos inseticidas é potencializada e de alto risco. Como testemunho, somente dois informantes do grupo de maior escolaridade perceberam o risco em relação ao uso de odorizantes.

A preferência por usar produtos sem cheiro ou com odor agradável é a principal escolha de compra do inseticida pelos dois grupos, que associam o odor agradável ou a ausência de cheiro à menor toxicidade do produto. Essa maquiagem é prova de que o interesse econômico da sociedade de consumo sobrepõe-se aos interesses da Saúde Pública. As estratégias mercadológicas, na maioria das vezes, induzem às práticas de risco, seja pela tendência a descaracterizar o potencial de riscos, seja por incentivar o consumo ${ }^{29}$.

Esse tipo de estratégia fere os preceitos básicos do Conselho Nacional de Autorregulamentação Publicitária (CONAR), que define a ética publicitária pela qual "[...] todo anúncio deve ser honesto e verdadeiro e respeitar as leis do país" e "[...] deve ser preparado com o devido senso de responsabilidade social", o que respeitaria o artigo 59, da Lei $n^{\circ} 6.360$, de 23 de setembro de $1976^{2}$. Ainda no que tange especificamente à propaganda e à rotulagem, o Artigo 59 define que:

Art. 59 - Não poderão constar de rotulagem ou de propaganda dos produtos de que trata esta Lei designações, nomes geográficos, símbolos, figuras, desenhos ou quaisquer indicações que possibilitem interpretação falsa, erro ou confusão quanto à origem, procedência, natureza, composição ou qualidade, que atribuam ao produto finalidades ou características diferentes daquelas que realmente possuam 
Esperar que programas de informação e de comunicação que atualizam o consumidor resultem da iniciativa da indústria e de suas agências de marketing e de publicidade não procede. Esse é papel do Estado, por meio dos órgãos públicos de saúde e do ambiente. É importante analisar as estratégias de comunicação que estão em curso na nossa sociedade. É preciso verificar de que modo estão abordando o aspecto da segurança dos produtos químicos utilizados nas residências. $\mathrm{O}$ cidadão, leigo no tema, não tem como associar as informações tecnicamente fornecidas no rótulo à sua exposição.

\section{CONSIDERAÇÕES FINAIS}

Enquanto a leitura e a compreensão dos rótulos dos inseticidas forem comprometidas pela utilização de uma linguagem técnica, com excesso de informação visando atender à legislação e desinformar o consumidor, a saúde do cidadão estará comprometida. É preciso equiparar a rotulagem dos desinfetantes domissanitários, que não possuem a classe toxicológica, aos dos agrotóxicos, que a apresentam por exigência da legislação, entretanto sem provocar no consumidor a fatiga ou a incompreensão dos rótulos, desestimulando sua leitura. Deveria haver, ao menos, a inclusão de frases de advertência nítidas nos rótulos dos inseticidas, como "Perigo, produto potencialmente tóxico". Ainda no campo da normatização, seria necessário buscar forças para se revogar a resolução RDC no 326, de 9 de novembro de $2005^{10}$, que permitiu a adição de odorizantes nos inseticidas, já que o forte odor era útil, ao menos, para afastar as pessoas do local de aplicação.

Outra medida importante seria a padronização da rotulagem e o descarte da embalagem dos inseticidas usados no ambiente doméstico, informando sua classe toxicológica e o risco ambiental. Afinal, utilizar estratégias de ocultamento de riscos do uso dos inseticidas, insinuando que são inócuos e que protegem a saúde e o ambiente, resulta na utilização indiscriminada desses produtos e na contaminação do meio. A isso segue o consequente aumento da resistência dos insetos, gerando elevação do consumo de inseticidas e ampliando o ainda subestimado risco de intoxicações.

\section{REFERÊNCIAS}

1. Brasil. Lei $\mathrm{n}^{\circ} 7.802$, de 11 de julho de 1989 . Dispõe sobre a pesquisa, a experimentação, a produção, a embalagem e rotulagem, o transporte, o armazenamento, a comercialização, a propaganda comercial, a utilização, a importação, a exportação, o destino final dos resíduos e embalagens, o registro, a classificação, o controle, a inspeção e a fiscalização de agrotóxicos, seus componentes e afins, e dá outras providências. Diário Oficial da União, Brasília, 12 de julho de 1989.

2. Brasil. Lei n ${ }^{\circ} 6.360$, de 23 de setembro de 1976. Dispõe sobre a Vigilância Sanitária a que ficam sujeitos os Medicamentos, as Drogas, os Insumos Farmacêuticos e Correlatos, Cosméticos, Saneantes e Outros Produtos, e dá outras Providências. Diário Oficial da União, Brasília, 24 de setembro de 1976.

3. Londres F. Agrotóxicos no Brasil: um guia para ação em defesa da vida. Rio de Janeiro: Assessoria e Serviços a Projetos em Agricultura Alternativa; 2011.

4. Presgrave RF, Camacho LAB, Villas Boas MHS. A profile of unintentional poisoning caused by household cleaning products, disinfectants and pesticides. Cad Saude Publica. 2008 Dec;24(12):2901-8. http://dx.doi. org/10.1590/S0102-311X2008001200019. PMid:19082281.

5. Meyer A, Sarcinelli PN, Abreu-Vilaça Y, Moreira JC. Os agrotóxicos e sua ação como desreguladores endócrinos. In: Peres F, Moreira JC. É veneno ou é remédio: agrotóxicos, saúde e ambiente. Rio de Janeiro: Fiocruz; 2003. p. 101-18.

6. Ferrari JA. Insecticide resistance. In: Beaty BJ, Marquardt WC, editor. Biology of disease vectors. Colorado: University of Colorado Press; 1996.

7. Braga IA, Valle D. Aedes aegypti: inseticidas, mecanismos de ação e resistência. EpidemiolServSaúde. 2007; 16(4):279-93.

8. Brogdon WG, McAllister JC. Insecticide resistance and vector control. Emerg Infect Dis. 1998 Oct-Dec;4(4):605-13. http://dx.doi.org/10.3201/ eid0404.980410. PMid:9866736.
9. Augusto LGS. Inter-relações entre a saúde ambiental e a saúde do trabalhador e a atenção básica de saúde no SUS. In: ABRASCO. Caderno de Texto da I Conferência Nacional de Saúde Ambiental, Coordenação: GT Saúde e Ambiente. 2009. p. 105-8.

10. Brasil. Agência Nacional de Vigilância Sanitária - ANVISA. Resolução RDC n 326, de 9 de novembro de 2005. Diário Oficial da União, Brasília, 14 de novembro de 2005.

11. Rocha AM, Guerra AJT, Santos AG, Oliveira AC, Neves FO. Diagnóstico da degradação ambiental no bairro de Itaipu, Niterói, RJ. In: VII Simpósio Nacional de Controle de Erosão; 2001; Goiânia, GO. p. 1-11.

12. Brasil. Agência Nacional de Vigilância Sanitária - ANVISA. Resolução RDC no 34, de 16 de agosto de 2010. Diário Oficial da União, Brasília, 18 de agosto de 2010 .

13. Diel C, Facchini LA, Dall'Agnol MM. Inseticidas domésticos: padrão de uso segundo a renda per capita. Rev Saude Publica. 2003 Feb;37(1):83-90. http://dx.doi.org/10.1590/S0034-89102003000100013. PMid:12488924.

14. Malacco MAF. Uso doméstico de inseticidas em residências da cidade de Lagoa Santa, Minas Gerais, Brasil, 2003 [dissertação]. Belo Horizonte (MG): Escola de Veterinária, Universidade Federal de Minas Gerais; 2005.

15. Câmara No HF. Condições sanitárias do ambiente urbano e o uso de pesticidas domésticos: implicações para a saúde [dissertação] Recife (PE): Departamento de Estudos em Saúde Coletiva, Centro de Pesquisa Aggeu Magalhães, FIOCRUZ; 2000.

16. Câmara MCC, Marinho CLC, Guilam MC, Braga AMCB. A produção acadêmica sobre a rotulagem de alimentos no Brasil. Rev Panam Salud Publica. 2008 Jan;23(1):52-8. http://dx.doi.org/10.1590/S1020-49892008000100007. PMid:18291073.

17. Rico Méndez FG, Ochoa Jiménez LG, Ocaña Servín H, Escobedo Arenas G, Cabrera Ruiz MA, Jacobo Avila A. Efecto de dos plaguicidas intramuros 
en la función respiratoria de una población mexicana. Rev Alerg Mex. 2000 Mar-Apr;47(2):70-4. PMid:10872309.

18. Moreno Marí J, Meliá Llácer A, Oltra Moscardó MT, Jiménez Peydró R. Situación actual en españa de los aerosoles insecticidas registrados en Sanidad Ambiental para uso doméstico. Rev Esp Salud Publica. 2003 MayJun;77(3):383-91. http://dx.doi.org/10.1590/S1135-57272003000300008. PMid:12852331.

19. Brasil. Agência Nacional de Vigilância Sanitária - ANVISA. Resolução RDC no 174, de 8 de julho de 2003. Diário Oficial da União, Brasília, 9 de julho de 2003.

20. Brasil. Agência Nacional de Vigilância Sanitária - ANVISA. Portaria n ${ }^{\circ}$ 321, de 28 de julho de 1997. Diário Oficial da União, Brasília, 8 de agosto de 1997.

21. Marins BR, Jacob SC, Peres F. Avaliação qualitativa do hábito de leitura e entendimento: recepção das informações de produtos alimentícios. Ciênc. Tecnol. Aliment. 2008; 28(3):579-85. http://dx.doi.org/10.1590/S010120612008000300012.

22. Furnival AC, Pinheiro SM. O público e a compreensão da informação nos rótulos de alimentos: o caso dos transgênicos. Rev. Digit. Bibl. Cienc Inf. 2009; 7(1):1-19.

23. Fernandes LB, Machado SS, Vieira DAP. Avaliação qualitativa do hábito de leitura e entendimento dos rótulos de alimentos no município de Inhumas - GO. Instituto Federal de Educação, Ciência e Tecnologia de Goiás/IFG. In: IV Seminário de Iniciação Científica: Ciência, Tecnologia e Inovação; 2010 Set 16-17; Inhumas. 2010.
24. Farina M. Psicodinâmica das cores em publicidade. São Paulo: EDUSP; 1973.

25. Crepaldi L. A influência das cores na decisão de compras: um estudo do comportamento do consumidor no ABC paulista. In: VI Encontro dos Núcleos de Pesquisa em Comunicação da Intercom - Sociedade Brasileira de Estudos Interdisciplinares da Comunicação. XXIX Congresso Brasileiro de Ciências da Comunicação; 2006 Set 6-9; Brasília.

26. Rodrigues CDR. Perto do Alcance das Crianças: o papel dos personagens em propagandas de produtos de limpeza [mestrado]. São Paulo (SP): Universidade de São Paulo, Escola de Comunicações e Artes; 2009.

27. Nobrega GA, Dantas WS, Silva VP. Percepção ambiental de donas de casa sobre o uso de produtos químicos em domicílios e estratégias sustentáveis. Holos. 2010; 26(4):47-73. http://dx.doi.org/10.15628/holos.2010.435.

28. Brito AML, Duarte HAST. O princípio da vulnerabilidade e a defesa do consumidor no direito brasileiro: origem e consequências nas regras regulamentadoras dos contratos e da publicidade [Internet]. Jus Navigandi; 2006. [Citado em 2011 fev 06]. Disponível em: http://jus.uol.com.br/revista/ texto/8648.

29. Costa EA. Fundamentos da vigilância sanitária. In: Costa EA. (org.). Vigilância Sanitária: temas para debate. Salvador: EDUFBA; 2009. p. 11-36.

Recebido em: Nov. 10, 2014

Aprovado em: Jun. 03, 2015 